\title{
Increase in in Utero Exposure to a Migrant, 4,4'-Butylidenebis(6-t-butyl- $m$-cresol), from Nitrile-Butadiene Rubber Gloves on Brain Aromatase Activity in Male Rats
}

\author{
Kanako Satoh, * Ryouichi NonaKa, Dai Nakae, and Akio Ogata \\ Department of Environmental Health and Toxicology, Tokyo Metropolitan Institute of Public Health; 3-24-1 Hyakunin- \\ cho, Shinjuku-ku, Tokyo 169-0073, Japan. \\ Received October 1, 2009; accepted October 5, 2009; published online October 5, 2009
}

\begin{abstract}
4,4'-Butylidenebis(6-t-butyl-m-cresol) (BBBC) can be eluted from disposable gloves made of nitrile-butadiene rubber and possibly also detected in food. It has been reported that BBBC is an androgen and estrogen antagonist in vitro. Previously, BBBC $(1.0 \mathrm{mg} / \mathrm{kg}$ body weight (bw)/d) was subcutaneously administered to pregnant rats from gestation days 11 through 18, and the effects on male offspring (postnatal day 102) were examined. Altered levels and turnover of the monoamines dopamine, serotonin, and noradrenalin as well as their metabolites were detected. This report measured the level of serum testosterone following prenatal exposure to BBBC $(0.1,1.0,10 \mathrm{mg} / \mathrm{kg} \mathrm{bw} / \mathrm{d})$ in male rats, and measured aromatase activity of the hypothalamus-preoptic area with a close connection to the sexual differentiation and sexual behavior of BBBC-treated rat brains. The serum testosterone level rose depending on exposure, and aromatase activity of the basomedial nucleus of amygdale region was increased in the $\mathrm{BBBC}$-treated group compared with the control. These results suggested that prenatal exposure to $\mathrm{BBBC}$ affects the central nervous system of male rat offspring, and $\mathrm{BBBC}$ may be an endocrine disrupting-chemical during the fetal period, and might influence the functional development of the brain.
\end{abstract}

Key words nitrile-butadiene rubber glove; brain aromatase activity; amygdale region; testosterone; 4,4'-butylidenebis(6-t-butyl$m$-cresol); endocrine-disrupting chemical

Disposable gloves made of nitrile-butadiene rubber (NBR) are used for contact with foodstuffs rather than polyvinylchloride (PVC) gloves containing di(2-ethylhexyl) phthalate (DEHP), because endocrine-disruptive effects are suspected for phthalate diesters including DEHP, a widely used plasticizer, which was detected in packed lunches for sale at convenience stores and in-patients' meals in hospitals. ${ }^{1,2)}$ The endocrine-disrupting effects of phthalate diesters (including DEHP) and phthalic acid monoesters, a metabolite of phthalic acid, ${ }^{3)}$ have been studied previously along with the in vitro androgenic and estrogenic effects of phthalate diesters and phthalic acid mono esters. Hormonal effects of DEHP and mono(2-ethylhexyl)phthalate, a mono ester of DEHP, were not observed ${ }^{4)}$ or were very weak. ${ }^{5}$ However, as a result of the prohibition of PVC gloves, NBR gloves have been increasingly used for preparation of food. NBR gloves were rarely used in the food industry in Japan. ${ }^{1,2)}$ It is thought to be necessary to clarify the effect of chemicals that elutes from substitute from the viewpoint of preventing before a problem happens. Accordingly, 4,4' butylidenebis(6-t-butyl- $m$-cresol) (BBBC, CAS No. 85-60-9, Fig. 1) can be eluted from disposable gloves made of NBR, and the amount of BBBC eluted from NBR gloves was reported to be $4.22 \mathrm{mg} / \mathrm{cm}^{2}$. 6 ,7) Disposable gloves used during cooking or packaging are sprayed with $68 \%(\mathrm{w} / \mathrm{w})$ ethanol for disinfection. Alcohol sprayed onto disposable gloves increased the level of chemicals eluted into foods by $8-41$ -

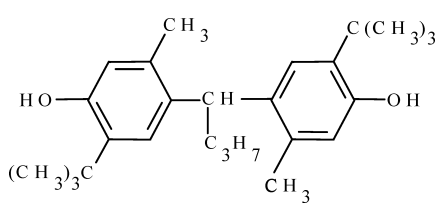

Fig. 1. The Structure of $4,4^{\prime}$-Butylidenebis(6- $t$-butyl- $m$-cresol) fold (possibly $\left.33.8-173.0 \mathrm{mg} / \mathrm{cm}^{2}\right)^{2)}$ The endocrine-disrupting effects of chemicals eluted from NBR gloves were examined using in vitro assays, and we reported that $\mathrm{BBBC}$ has the strongest androgen receptor (AR) and estrogen receptor (ER) antagonist activities (in the $10^{-6} \mathrm{M}$ range of $\mathrm{IC}_{50}$ values), and has the strong cell toxicity. ${ }^{8)}$ The strength of these activities was about 5 times higher than that of a known AR antagonist, 1,1'-(2,2-dichloroethylidene)bis[4-chlorobenzene] ( $p, p^{\prime}$-DDE), and similar to that of bisphenol A (BPA), which has strong AR antagonist and ER agonist activity. ${ }^{9,10)}$ Previous studies have also examined hormonal effects using in vivo assays ${ }^{11,12)}$ on some of the chemicals that showed strong positive effects using in vitro assays. ${ }^{4,8-10,13-16)}$

Endocrine disruptors (EDs) show adverse effects on development and/or function of the reproductive system and nervous system, particularly when exposure occurs in the fetus or neonates. Evidence indicates that certain behaviors are especially responsive to ED exposure during gestation, and that one index of susceptibility may be reflected in the differing responses of male and female offspring, a phenomenon termed sexual dimorphism. ${ }^{17)}$ The action mechanism of EDs in the central nervous system is complex. Endocrine disruption caused by ingestion of trace amounts of chemicals induces abnormal thyroid metabolism and inhibits functional development of the brain in children, and this may be a cause of mental retardation and behavioral abnormalities. ${ }^{17-19)}$ It is believed that the entrance of harmful substances into the brain is generally prevented by the blood-brain barrier. However, the blood-brain barrier is undeveloped in fetuses, and chemical substances enter the fetal brain via the placenta. In addition, many environmental chemical substances are lipidsoluble, which pass more easily through the blood-brain barrier. Such chemical substances accumulate in fat-rich breast milk, resulting in exposure of the neonatal brain to a relatively high concentration of chemical substances. Moreover, 
the ability to metabolize and excrete these chemical substances is incomplete in infants because liver and kidney functions are undeveloped. Accordingly, a trace amount of chemical substances may markedly influence the endocrine and cranial nervous systems in the fetal period and infancy, and it has been suggested that impairment of the nervous system is very likely to result in irreversible conditions. ${ }^{20)}$ As evidence of this effect, low IQ and memory and attention deficits in children born from mothers who ate a large amount of polychlorinated biphenyl (PCB)-containing fish have been reported. ${ }^{21)}$ Abnormal behavior after growth and influences on neurotransmitters in the brain, including dopamine (DA), serotonin (5-HT), and noradrenalin (NA), due to PCB exposure during the fetal period were also clarified in experimental animals in basic studies. ${ }^{22,23)}$ Mizuo et $a l .{ }^{18)}$ reported neurobehavioral toxicity of BPA exposure during the fetal period and infancy. Based on this viewpoint, we have reported studies ${ }^{11,12)}$ on the influence of exposure to trace amounts of chemical substances during the rat fetal period $(11-18 \mathrm{~d}$ of gestation, at which stage the monoamine neurotransmission system may develop) followed by feeding with milk from the exposed mother after birth.

NOAEL (non observed adverse effect level) and LOAEL (lowest observed adverse effect level) of BBBC have not been determined because in vivo studies examining $\mathrm{BBBC}$ mediated endocrine disruption have not been attended now. We are investigating prenatal exposure to $\mathrm{BBBC}$ in rats to further clarify whether $\mathrm{BBBC}$ is an endocrine-disrupting chemical. When the effects of BBBC on the offspring of pregnant rats were examined using in vivo assays, ${ }^{11,12)}$ the absolute weights of rat brains exposed to $1.0 \mathrm{mg} / \mathrm{kg}$ body weight (bw)/d BBBC were significantly decreased, but the relative weights were not changed, and the change in absolute and relative brain weights with $0.1 \mathrm{mg} / \mathrm{kg}$ bw BBBC-treated rats were not significant. ${ }^{24)}$ Furthermore, the levels of the monoamines were measured as well as their metabolites in the brains of exposed rats to clarify the influence of $\mathrm{BBBC}$ on the central nervous system. ${ }^{24)}$ Altered levels and turnover of these three monoamines (DA, 5-HT, and NA) as well as their metabolites were detected. These results suggested that prenatal exposure to $\mathrm{BBBC}$ affects the central nervous system of male rat offspring, and $\mathrm{BBBC}$ may be an endocrinedisrupting chemical during the fetal period.

In this report, the level of serum testosterone following prenatal exposure to $\mathrm{BBBC}$ was measured in male rats, and testosterone levels were found to be higher than in control rats. From this result, it was attempted to measure aromatase activity in the hypothalamus-preoptic area (HPOA), which has a close connection to sexual differentiation and sexual behavior of BBBC-treated rat brains. Aromatase (an isoform of P450; CYP 19) is a key enzyme in the conversion of androgens to estrogens and has an important role in maintaining a homeostatic balance between androgen and estrogen.

\section{MATERIALS AND METHODS}

Reagents $\mathrm{BBBC}$ was purchased from Tokyo Kasei Industry, Co., Ltd. (Tokyo, Japan, purity: $>97 \%$ by HPLC). ${ }^{8}$ An estrone enzyme immunoassay (EIA) kit was purchased from Cosmo Bio. Co., Ltd. (Tokyo, Japan). 4-Hydroxy-androstene-3,17-dion, phenylmethylsulfonyl fluoride (PMSF), and $\beta$-nicotinamide-adenine dinucleotide phosphate (NADPH) were purchased from Sigma (St. Louis, MO, U.S.A.). Other reagents were of the highest grade available commercially.

Animals and Experimental Protocol Pregnant, specific-pathogen-free Sprague-Dawley rats (9 weeks old, $n=32$ ) purchased from Charles River Japan (Kanagawa, Japan) were received on day 7 of gestation and housed individually with woodchip bedding (Clea-chip, CLEA Japan Inc., Tokyo, Japan). All animals were maintained under controlled conditions at $22-24{ }^{\circ} \mathrm{C}, 45-65 \%$ humidity, $12-\mathrm{h}$ lighting, and 10 ventilations per hour. The animals were given free access to general food (CE-2, Clea Japan Inc., Tokyo, Japan) and water. Observation of the general condition and measurements of body weight were performed daily. All animal studies were performed in accordance with the NIH Guidelines for the Care and Use of Laboratory Animals.

The experimental protocol was determined in accordance with the previous paper. ${ }^{24)}$ After an acclimatization period of $4 \mathrm{~d}$, rats were divided into three groups. BBBC was dissolved in ethanol, and this solution was diluted with saline $(1 \%$ ethanol solution). BBBC $(n=8 ; 0.1,1.0$, and $10 \mathrm{mg} / \mathrm{kg} \mathrm{bw} / \mathrm{d}$ saline solution at a volume of $1.0 \mathrm{ml} / 100 \mathrm{~g} \mathrm{bw}$; respectively) or $1 \%$ ethanol-saline solution at a volume of $1.0 \mathrm{ml} / 100 \mathrm{~g} \mathrm{bw}$ ( $n=8$, control) was administered subcutaneously to pregnant rats once a day for $8 \mathrm{~d}$ from gestation days 11 through 18 (during which the monoamine nervous systems develop and mature). Four male rat offspring born from one mother were selected at random and kept with the litters until weaning $(0.1,1.0$, and $10 \mathrm{mg} / \mathrm{kg}$ bw BBBC-treated rats $n=32$, respectively; control rats, $n=32$ ). Aromatase activity in the HPOA of the male was higher than that of the female, and because aromatase activity was too low for the female after the PND 21 , it was not possible to measure it. ${ }^{25)}$ Therefore, only the male was executed.

Male rat offspring were housed individually in stainless cages from postnatal day (PND) 25 (day of birth=PND 0). The body weight of male rat offspring was recorded at frequent intervals until the terminal day. Male rat offspring were sacrificed on PND 102 (after maturation) as described previously $^{24)}$ under ether anesthesia. After blood collection, brains were removed, weighed, and stored at $-80^{\circ} \mathrm{C}$ until measurement.

Measurement of Serum Testosterone Level Serum was preserved at $-80^{\circ} \mathrm{C}$ until measurement. The serum concentration of testosterone was measured using an EIA kit (Cayman Chemicals; Ann Arbor, MI, U.S.A.). This measurement was in accordance with the method reported previously. ${ }^{12}$ )

Preparation of Homogenates The brains, stored at $-80^{\circ} \mathrm{C}$, of the control and 1.0 and $10 \mathrm{mg} / \mathrm{kg} \mathrm{bw} \mathrm{BBBC}$ treated groups were kept at $-20^{\circ} \mathrm{C}$ for about $1 \mathrm{~h}$, and $800 \mathrm{~mm}$-thick coronal sections were prepared using a cryostat. Brain regions including the bed nucleus of the stria terminalis (BNST), preoptic area (PA), anterior hypothalamic nucleus (AHN), basomedial nucleus of amygdale (BNA), and ventromedial hypothalamic nucleus (VHN), were dissected out from frozen brains with a brain blocker. Dissected tissues were stored at $-80^{\circ} \mathrm{C}$ until use. These tissues (BNST, PA, AHN, BNA, and VHN) were homogenized in 150,120 , 120,300 , and $150 \mu \mathrm{l}$ of steroidogenic buffer $(20 \mathrm{~mm} \mathrm{~N}$ tris(hydroxymethyl)methyl-2-aminoethane-sulfonic acid (TES), $10 \mathrm{~mm}$ ethylenediaminetetraacetic acid (EDTA), 
$150 \mathrm{~mm} \mathrm{KCl,} \mathrm{0.1} \mathrm{mM} \mathrm{PMSF,} \mathrm{pH} \mathrm{7.3),} \mathrm{respectively,} \mathrm{and} \mathrm{pro-}$ tein levels were determined according to the method of Bradford. $^{26)}$

Aromatase Assay Aromatase levels were determined in accordance with the method reported previously. ${ }^{27)}$ Briefly, a reaction mixture contained $20 \mu \mathrm{l}$ of homogenate, $10 \mathrm{~mm}$ NADPH， $200 \mathrm{~nm}$ 4-hydroxy-androstene-3,17-dione, and $50 \mathrm{~mm}$ phosphate buffer $(\mathrm{pH} 7.5)$ at a final incubation volume of $120 \mu \mathrm{l}$. Incubations were performed at $37^{\circ} \mathrm{C}$ for $30 \mathrm{~min}$, and were terminated by heating at $100{ }^{\circ} \mathrm{C}$ for $10 \mathrm{~min}$.

Measurement of Aromatase Activity One hundred microliters of the reaction mixture was used as the sample for analysis using an estrone EIA kit as described previously. ${ }^{27}$ Briefly, goat anti-rabbit immunoglobulin G ( $\mathrm{IgG}$ )-coated 96 well microplate was washed using a wash solution, and then a solution of biotin-labeled estrone, estrone standard or chemicals, and estrone-specific antibody were reacted at $4{ }^{\circ} \mathrm{C}$ overnight (17-19h). After aspirating the solution and washing all wells 3 times with a wash solution, and the substrate solution was added into all wells at $25^{\circ} \mathrm{C}$ for $2 \mathrm{~h}$. After the fourth wash, a solution of the $o$-phenylenediamine was added at $25^{\circ} \mathrm{C}$ for $20 \mathrm{~min}$, and then stop solution was added into all wells. The developed color was read at $450 \mathrm{~nm}$ using a micro-titer spectrophotometer (SunriseRemote, TECAN, Copenhagen, Denmark), and the estrone concentration was calculated based on a standard curve (eight estrone concentrations; $0,1.2,4.8,19.5,78.1,312.5,1250$, and $5000 \mathrm{pg} / \mathrm{ml}$ ) using the manufacturer's software.

Statistical Analysis All statistical analysis and $\mathrm{IC}_{50}$ values were determined using KaleidaGraph ver. 4 software (Synergy Software, PA, U.S.A.). Differences between groups were assessed for statistical significance by Student's $t$-test. Differences with $p<0.05$ were considered significant. Data are expressed as means \pm S.D.

\section{RESULTS}

General Condition There was no difference in the birth number per mother, and no effect on the male/female ratio was found for BBBC. The treatments induced no maternal toxicity. No abnormal behavior or appearance or diarrhea was noted at PND 102 in any of the control or BBBC treatment groups $(0.1,1.0$ and $10 \mathrm{mg} / \mathrm{kg} \mathrm{bw})$, and all animals survived until completion of administration. There were no differences in liver or kidney weight or the histological changes between BBBC-treated rats and control rats at PND 102. Differences in serum levels of aspartate aminotransferase, alanine aminotransferase, cholesterol, triglyceride, and glucose etc. were not observed. There was no effect on $1 \%$ ethanolsaline treated rat. ${ }^{12}$ )

Table 1. Body Weights in Male Rat Offspring Prenatally Exposed to BBBC
Body Weight Body weights were measured during the PND 2-102 period (Table 1). Significant differences in body weight in the $0,0.1,1.0$, and $10 \mathrm{mg} / \mathrm{kg}$ bw BBBCtreated group at PND 102 were not observed. However, the body weight at lactation decreased in the 1.0 and $10 \mathrm{mg} / \mathrm{kg} \mathrm{bw}$ BBBC-treated groups. In the $1.0 \mathrm{mg} / \mathrm{kg} \mathrm{bw}$ BBBC-treated group significant decreases were observed at PND 2, 13, and 17 compared with the corresponding control values. In the $10 \mathrm{mg} / \mathrm{kg}$ bw BBBC-treated group, significant decreases in body weight were observed at PND 2, 10, 13, 17,20 , and 24 compared with the corresponding control values. Significant differences in body weight after delactation were not observed. Body weights in the $0.1 \mathrm{mg} / \mathrm{kg} \mathrm{bw}$ BBBC-treated group during PND 2-102 were not changed.

Brain Weight Significant decreases $(p=0.01)$ in brain absolute weights from $2.25 \mathrm{~g}$ (control, $n=32$ ) to $2.19 \mathrm{~g}$ (exposed to $1.0 \mathrm{mg} / \mathrm{kg}$ bw $\mathrm{BBBC}, n=32$ ) were observed in rat offspring prenatally exposed to BBBC (data not shown). However, the relative weights per $100 \mathrm{~g}$ bw were not changed (1.0 mg/kg bw BBBC-treated: $419 \mathrm{mg}$, control: $423 \mathrm{mg}$ ). Differences in the brain absolute and relative weights between the 0.1 and $10 \mathrm{mg} / \mathrm{kg}$ bw BBBC-treated groups were not observed.

Serum Testosterone Levels The serum testosterone levels in male rats were measured at PND 102 (Fig. 2). The serum testosterone level was significantly higher in the $1.0 \mathrm{mg} / \mathrm{kg} \mathrm{bw}(6.08 \pm 2.96 \mathrm{ng} / \mathrm{ml})$ and $10 \mathrm{mg} / \mathrm{kg} \mathrm{bw}(7.09 \pm$ $4.72 \mathrm{ng} / \mathrm{ml}) \mathrm{BBBC}$-treated groups than in the control group $(2.79 \pm 1.31 \mathrm{ng} / \mathrm{ml})$. No significant differences between the $0.1 \mathrm{mg} / \mathrm{kg}$ bw BBBC-treated group $(3.49 \pm 1.26 \mathrm{ng} / \mathrm{ml})$ and the control group were noted.

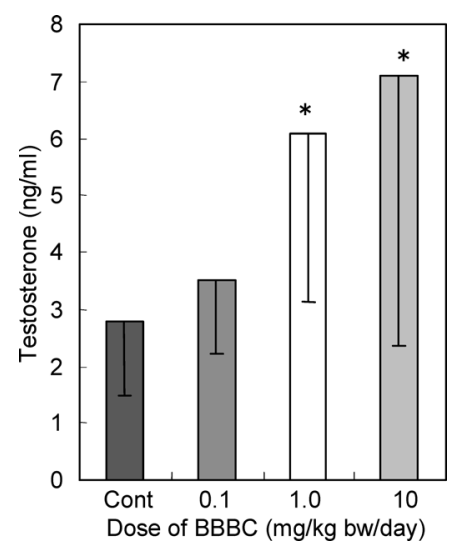

Fig. 2. Effects of BBBC Treatment on Serum Testosterone Levels in Male Rats

$\operatorname{BBBC}(0.1,1.0$, and $10 \mathrm{mg} / \mathrm{kg}$ bw) was administered subcutaneously to pregnant SD rats as described in Materials and Methods. The control group received 1\% ethanol in saline. Bars denote S.D. $n=12$. * Significantly different $(p<0.01)$ from the control.

\begin{tabular}{|c|c|c|c|c|c|c|c|c|c|}
\hline \multirow{2}{*}{$\begin{array}{c}\text { Dose of BBBC } \\
(\mathrm{mg} / \mathrm{kg} \text { bw/d) }\end{array}$} & \multirow{2}{*}{$n^{a)}$} & \multicolumn{8}{|c|}{ Body weight (g) } \\
\hline & & $\mathrm{PND}^{b)} 2$ & PND 5 & PND 10 & PND 13 & PND 17 & PND 20 & PND 24 & PND 102 \\
\hline 0 & 32 & $8.2 \pm 0.7$ & $13.9 \pm 1.4$ & $26.1 \pm 2.7$ & $34.6 \pm 3.1$ & $44.5 \pm 3.4$ & $54.9 \pm 6.2$ & $76.3 \pm 7.4$ & $531.9 \pm 26.6$ \\
\hline 0.1 & 32 & $8.2 \pm 0.8$ & $14.3 \pm 1.2$ & $26.1 \pm 2.1$ & $33.9 \pm 2.4$ & $43.7 \pm 2.8$ & $56.4 \pm 3.7$ & $79.1 \pm 5.3$ & $529.9 \pm 41.6$ \\
\hline 1.0 & 32 & $7.8 \pm 0.7^{*}$ & $13.6 \pm 1.0$ & $25.5 \pm 1.9$ & $33.2 \pm 2.3^{*}$ & $42.4 \pm 3.1^{* *}$ & $53.7 \pm 4.0$ & $74.1 \pm 3.9$ & $525.9 \pm 43.2$ \\
\hline 10 & 32 & $7.7 \pm 0.9 *$ & $13.2 \pm 1.6$ & $24.8 \pm 2.6^{*}$ & $31.7 \pm 2.8^{* * *}$ & $40.5 \pm 3.0^{* *}$ & $51.7 \pm 3.8^{*}$ & $70.9 \pm 4.7 * *$ & $519.0 \pm 44.1$ \\
\hline
\end{tabular}

$\operatorname{BBBC}(0.1,1.0$, and $10 \mathrm{mg} / \mathrm{kg} \mathrm{bw})$ was administered subcutaneously to pregnant SD rats as described in Materials and Methods. The control group ( $0 \mathrm{mg} / \mathrm{kg}$ bw) received $1 \%$ ethanol in saline. $a$ ) Number of animals; $b$ ) PND: postnatal day (day of birth $=$ PND 0 ). Each value is the mean \pm S.D. Significantly different $(* p<0.05$, $* * p<0.01)$ from the control. 
Table 2. Effects of BBBC Treatment on Aromatase Activity in Male Rat Brain

\begin{tabular}{|c|c|c|c|c|}
\hline \multirow{2}{*}{ Brain region } & \multicolumn{4}{|c|}{ Aromatase activity (pg/mg protein) } \\
\hline & Control $\left(n^{a)}=6\right)$ & $1.0 \mathrm{mg} \mathrm{BBBC}(n=6)$ & Control $(n=9)$ & $10 \mathrm{mg} \mathrm{BBBC}(n=12)$ \\
\hline Bed nucleus of stria terminalis & $23.40 \pm 14.51$ & $22.27 \pm 9.53$ & $22.28 \pm 11.05$ & $29.15 \pm 12.60$ \\
\hline Preoptic area & $51.55 \pm 29.77$ & $61.41 \pm 26.61$ & $57.04 \pm 16.99$ & $46.04 \pm 15.28$ \\
\hline Anterior hypothalamic nucleus & $76.26 \pm 57.04$ & $82.26 \pm 48.41$ & $68.23 \pm 16.67$ & $55.27 \pm 12.05$ \\
\hline Basomedial nucleus of amygdale & $47.00 \pm 26.57$ & $106.18 \pm 47.83 *$ & $50.03 \pm 10.70$ & $73.81 \pm 22.26^{*}$ \\
\hline Ventromedial hypothalamic nucleus & $20.71 \pm 9.83$ & $19.31 \pm 7.26$ & $19.35 \pm 6.26$ & $20.18 \pm 7.68$ \\
\hline
\end{tabular}

BBBC (1.0 and $10 \mathrm{mg} / \mathrm{kg} \mathrm{bw})$ was administered subcutaneously to pregnant SD rats as described in Materials and Methods. The control group received $1 \%$ ethanol in saline. a) Number of animals. Each value is the mean \pm S.D. $*$ Significantly different $(p<0.01)$ from the control.

Effects of BBBC on Brain Aromatase Activity The brain aromatase activity was measured at the same time by EIA and radioisotope (RI) methods, and the values obtained were compared between each other as well as with rat ovarian microsomes. The values obtained using the EIA and RI methods were positively correlated, with a Pearson's correlation coefficient of $0.91 \quad(p<0.01)$ (data not shown). Aromatase activities were measured in the BNST, PA, AHN, $\mathrm{BNA}$, and $\mathrm{VHN}$ regions of rat brain of the 1.0 and $10 \mathrm{mg} / \mathrm{kg}$ bw BBBC-treated groups (Table 2). In the BNA region, aromatase activities were significantly increased in the 1.0 and $10 \mathrm{mg} / \mathrm{kg}$ bw BBBC-treated groups compared with the control group. In the BNST, PA, AHN, and VHN regions, no differences were observed between the two groups.

\section{DISCUSSION}

It was reported previously that $\mathrm{BBBC}$ exhibited a stronger anti-androgen effect than $p, p^{\prime}$-DDE and an anti-estrogen effect comparative to that of BPA in an in vitro study. ${ }^{8)} \mathrm{Be}$ cause the actions of chemicals suspected be EDs are not limited to the reproductive system, and hormone receptors are abundantly localized in the cranial nervous system, serious influences of environmental chemical substances on the functional development of the brain, sexual differentiation, and behavioral development are of concern. ${ }^{19)}$ We have reported studies ${ }^{11,12)}$ on the influence of exposure to trace amounts of chemical substances during the rat fetal period followed by feeding with milk from the exposed mother after birth. Rat fetuses were exposed to BBBC $(1.0 \mathrm{mg} / \mathrm{kg} \mathrm{bw})$ using this in vivo system, and decreased brain absolute weight was found at PND 102, as well as altered levels of neurotransmitters, their metabolites, and their metabolic rate in the brain. ${ }^{24)}$

In this study, fetuses were exposed to $10 \mathrm{mg} / \mathrm{kg}$ bw BBBC, 10 times higher than the dose that influenced brain weight, using the in vivo system, similarly to that in the previous report. ${ }^{24)}$ No abnormality during pregnancy or changes in the weights of main organs, including the brain, macroscopic observations, or serology/biochemistry were noted, but the body weight during the nursing period was significantly lower in animals exposed to $1.0 \mathrm{mg} / \mathrm{kg}$ BBBC than those in the control group. Measurement of the serum testosterone level showed a significant increase in a manner dependent on the dose of BBBC. Based on these findings, it was assumed that aromatase, an enzyme converting androgen to estrogen already expressed in the fetal brain, was affected. Because androgen promotes aromatase expression in the brain, when the blood androgen level rises, aromatization occurs in brain cells and increases the estrogen level (aromatase hypothesis). ${ }^{28,29)}$ BNST, PA, AHN, BNA, and VHN of the HPOA are reportedly closely related to sexual differentiation and behavior, and the express aromatase at a high level. ${ }^{30,31)}$ The aromatase activity level in these regions was measured in the groups treated with 1.0 and $10 \mathrm{mg} / \mathrm{kg}$ bw BBBC, in which the serum testosterone level was increased significantly. A sensitive EIA $^{27)}$ for aromatase activity measurement was employed, rather than the conventional method using $\mathrm{RI}{ }^{32)}$ by which a very low amount in individual brain regions, not the entire HPOA, could be measured.

Considering that letrozole (aromatase inhibitor) has been reported to significantly elevate the serum testosterone level in healthy adult men, ${ }^{33}$ the finding that the serum testosterone level rose in male rats in a manner dependent on the fetal BBBC exposure level suggests that BBBC acted as an aromatase inhibitor in vivo. In addition, the brain aromatase activity level rose significantly as expected based on the aromatase hypothesis. Furthermore, the fact that the activity level rose in the BNA indicates that the amygdale ${ }^{34)}$ is not only involved in the sexual differentiation of the brain and reproductive behavior but also responsible for the regulation of endocrine function, memory, cognition, and emotional behavior, and all kinds of information, such as auditory and visual sensations, are collected in this region. Considering the previously reported changes in neurotransmitters in the brain, $\mathrm{BBBC}$ exposure during the fetal period may impair the nervous system similarly to PCB and BPA. The incidence of developmental disorders of the brain in children, such as abnormal behavior, attention-deficit hyperactivity disorder, and autism, has increased recently, and environmental chemical substances are considered to influence intelligence and behavior in children, i.e., functional development of the brain may be affected. ${ }^{19)}$ Although it was unclear why the absolute brain weight was altered only at a BBBC exposure dose of $1.0 \mathrm{mg} / \mathrm{kg}$, it was suggested that $\mathrm{BBBC}$ exposure during the fetal period may influence functional development of the brain and subsequently behavior. Thus, it may be necessary to investigate behavior at PND 102, aromatase activity and testosterone level of the brain during the fetal period, and integrative function of the brain during the nursing period, in which the body weight was significantly lower. Furthermore, based on a report in which the level of thyroid hormone, which influences intellectual development of the brain, was altered in animals with reduced behavior and memorizing ability following PCB exposure during the fetal period, ${ }^{35)}$ measurements of thyroid-related hormones in sera of animals exposed to $\mathrm{BBBC}$ during the fetal period are currently being 
performed.

Acknowledgments Dr. K. Ohyama, Mr. H. Takahashi, Mr. H. Ando, Mr. Y. Kubo, Mr. A. Nagasawa, Mr. K. Yuzawa, and Mr. N. Yano are gratefully acknowledged for their excellent and valuable technical assistance.

\section{REFERENCES}

1) Tsumura Y., Ishimitsu S., Nakamura Y., Yoshii K., Kaihara A., Tonogai Y., Shokuhin Eiseigaku Zasshi, 42, 128-132 (2001).

2) Tsumura Y., Ishimitsu S., Kaihara A., Yoshii K., Nakamura Y., Tonogai Y., Food Addit. Contam., 18, 569-579 (2001).

3) Eigenberg D. A., Bozigian H. P., Carter D. E., Sipes I. G., J. Toxicol. Environ. Health, 17, 445-456 (1986).

4) Satoh K., Nonaka R., Ikeda M., Satoh T., Kamimura H., Nagai F., Ann. Rep. Tokyo Metro. Inst. Pub. Health, 55, 307-314 (2004).

5) Takeuchi S., Iida M., Kobayashi S., Matsuda T., Kojima H., Toxicology, 210, 223-233 (2005).

6) Mutsuga M., Wakui C., Kawamura Y., Maitani T., Food Addit. Contam., 19, 1097-1103 (2002).

7) Mutsuga M., Kawamura Y., Waku C., Maitani T., Shokuhin Eiseigaku Zasshi, 44, 103-109 (2003).

8) Satoh K., Nonaka R., Ohyama K., Nagai F., Ogata A., Iida M., Biol. Pharm. Bull., 31, 375-379 (2008).

9) Satoh K., Ohyama K., Aoki N., Iida M., Nagai F., Food Chem. Toxicol., 42, 983-993 (2004).

10) Satoh K., Nonaka R., Ohyama K., Nagai F., J. Health Sci., 51, $557-$ 568 (2005)

11) Sakamoto Y., Satoh K., Ando H., Kubo Y., Nagasawa A., Yano N., Yuzawa K., Takahashi H., Ogata A., Kamimura H., Ann. Rep. Tokyo Metro. Inst. Pub. Health, 56, 343-346 (2005).

12) Ohyama K., Satoh K., Sakamoto Y., Ogata A., Nagai F., Exp. Biol.
Med., 232, 301-308 (2007).

13) Satoh K., Nagai F., Aoki N., Nishijima M., J. Pharm. Soc. Japan, 120, 1429-1433 (2000).

14) Satoh K., Nagai F., Aoki N., J. Health Sci., 47, 495-501 (2001).

15) Satoh K., Nagai F., Ann. Rep. Tokyo Metro. Inst. Pub. Health, 53, 265-267 (2002).

16) Satoh K., F.F.I. J., 212, 398-414 (2007).

17) Weiss B., Environ. Health Perspect., 110 (Suppl.), 387-391 (2002).

18) Mizuo K., Narita M., Suzuki T., Brain Sci., 25, 1133-1140 (2003).

19) Kurado J., Sci. J. Kagaku, 73, 1234-1243 (2003).

20) Kawahara M., Kuroda Y., Igaku No Ayumi, 201, 159-161 (2002).

21) Jacobson J. L., Jacobson S. W., N. Engl. J. Med., 335, 783-789 (1996).

22) Schantz S. L., Seo B. W., Wong P. W., Pessah I. N., Neurotoxicology, 18, 457-467 (1997)

23) Seegal R. F., Bush B., Brosch K. O., Toxicology, 86, $71-87$ (1994)

24) Satoh K., Nonaka R., Ohashi N., Shimizu M., Oshio S., Takeda K., Biol. Pharm. Bull., 31, 2211-2215 (2008).

25) Takahashi Y., Kitakanto-Igaku, 38, 449-464 (1988).

26) Bradford M. M., Anal. Biochem., 72, 248-254 (1976).

27) Satoh K., Nonaka R., Ishikawa F., Ogata A., Nagai F., Biol. Pharm Bull., 31, 357-362 (2008).

28) Roselli C., Klosterman S. A., Endocrinology, 139, 3193-3201 (1998).

29) Baum M. J., Tobet S. A., Physiol. Behav., 37, 111-1118 (1986).

30) Balthazart J., Foidart A., Harada N., Brain Res., 122, 137-148 (1990).

31) Balthazart J., Foidart A., Surlemont C., Harada N., Cell Tissue Res., 263, 71-79 (1991)

32) Satoh K., Sakamoto Y., Ogata A., Nagai F., Mikuriya H., Numazawa M., Yamada K,. Aoki N., Food Chem. Toxicol., 40, 925-933 (2002).

33) Raven G., Jong F. H., Kaufman J. M., Ronde W., J. Clin. Endocrinol. Metab., 91, 3324-3328 (2006).

34) Sakuma Y., Clin. Neurosci., 5, 166-167 (1987).

35) Shishiba Y., Igaku No Ayumi, 201, 127-132 (2002). 